\title{
Ardahan'da kullanılan kömürün hava kirliliğine etkisinin incelenmesi
}

\author{
Rövşen GULIYEV*, Mustafa AKGÜN \\ Ardahan Üniversitesi, Mühendislik Fakültesi, Çevre Mühendisliği Bölümü, Yenisey kampüsü, Ardahan
}

Geliș Tarihi (Received Date): 03.09.2019

Kabul Tarihi (Accepted Date): 30.01.2020

$\ddot{\mathbf{O} z}$

Bu çalışmada Ardahan'da ısınma amaçlı kullanılan kömürün kalorisinin, çevreye verilen kükürt dioksit gazının ve kül miktarının belirlenmesi amaçlanmıştır. Bunun için Ardahan ili genelinde (Ardahan Merkez, Ardahan Halil Efendi Mahallesi, Göle, Çıldır, Damal, Posof, Hanak İlçeleri) kullanılan kömürün miktarı ve kalitesi (içeriğindeki kükürt miktarı, nemi, sabit karbon miktarl ve üst isl değeri) tespit edilmiştir. Ardahan ili genelinde 10/2017-09/2018 tarihleri arast 22172 ton ithal kömür ve 10835 ton yerli kömür kullanıldığ $\iota$ belirlenmiştir. Kalite tespiti için örnek alınan kömürler değirmende ögütüldükten sonra 100 mesh elekten geçirilerek analize hazırlanmıştır. Analize hazırlanmış kömürlerde Üst Isı Değeri (kcal/kg), Kükürt (S) (\%), Nem (\%), Kül (\%), Uçucu Madde (\%), Sabit Karbon (\%) analizleri yapılmıştır.

Anahtar kelimeler: Hava kirliliği, kömür, kül, kükürt dioksit.

\section{Investigation of the effect of coal used air polution in Ardahan}

\begin{abstract}
The aim of this study is to determine the calorie of coal used for heating purposes in Ardahan, and the amount of sulfur dioxide and ash to be given to the environment. The amount and quality of the coal used in Ardahan Province (Ardahan Center, Ardahan Halil Efendi district, Göle, Çıldır, Damal, Posof, Hanak counties) in Ardahan Province (amount of sulfur, content of moisture, amount of fixed carbon and upper heat value) were determined. 22172 tons of imported coal and 10835 tons of domestic coal were used between 10/2017 and 09/2018 in Ardahan Province. The charcoal samples for quality determination were milled after milling at 100 mill sieves and prepared for
\end{abstract}

\footnotetext{
* Rövşen GULIYEV, rovsenguliyev@ardahan.edu.tr, http://orcid.org/0000-0003-2396-8201

Mustafa AKGÜN, mustafaakgun@ardahan.edu.tr, http://orcid.org/0000-0002-7172-1855
} 
analysis. Analysis of Upper Heat Value (kcal / kg), Sulfur (S) (\%), Moisture (\%), Ash (\%), Volatile Substance (\%), Hard Carbon (\%) were performed in the analyzed coal.

Keywords: Air pollition, coal, ash, sulfur dioxide.

\section{Giriş}

Günümüzün üzerinde durulan önemli çevre konularından birisi temiz sürdürülebilir, çevre dostu hammadde kullanılmasıdır. Çünkü hava kirliliği her geçen gün artmaktadır ve bu kirliliğin artmasında enerji elde etmek amacıyla kullanılan fosil yakıtların etkisi oldukça yüksektir [1]. Bilindiği gibi endüstride ve 1sınma başta olmak üzere birçok farklı alanda en çok kullanılan fosil yakıtlardan biri kömürdür. Isınma amacı için kullanılan fosil yakıt olan kömürün kullanım oranı yıldan yıla artmaktadır [1-3].

Kömürün içerisinde bulunan safsızlıklar; yanma prosesindeki havanın miktarından, havanın veriliş şeklinden, yanma sıcaklığının yüksekliğinden ve çeşitli nedenlerden etkilenerek kirletici olarak kabul edilen gazları ve parçacıkları oluşturarak çevrenin kirlenmesine neden olur [4]. Kömürün yanma mekanizması çok karmaşık bir kimyasal süreçtir. Ortam şartlarına bağlı olarak karmaşıklık daha da artabilir [5]. Kömürün içeriğinde olan karbon (C) ve kükürt (S) ile havada bulunan oksijen arasında aşağıdaki gibi bir reaksiyon gerçekleşmektedir.

$\mathrm{C}+\mathrm{O}_{2} \rightarrow \mathrm{CO}_{2}+\mathrm{Q}_{1}$

$\mathrm{S}+\mathrm{O}_{2} \rightarrow \mathrm{SO}_{2}+\mathrm{Q}_{2}$

Görüldüğü gibi reaksiyon sonucunda karbon dioksit, kükürt dioksit ve 1sı açığa çıkar. Eğer tüm karbonları yakmaya yetecek kadar oksijen yoksa o zaman tam yanma olmaz ve karbon monoksit (CO) oluşur [6]. Yakıtın oksitlendiği bir ortamda bütün elemanlar oksitlenmiş olarak $\mathrm{CO}_{2}, \mathrm{CO}, \mathrm{H}_{2} \mathrm{O}, \mathrm{NOx}$ ve $\mathrm{SO}_{2}$ halinde ortamı terk ederler [7].

Kirleticiler kaynaktan salındıktan sonra kısa sürede geniş alanlara yayılarak hava kirliliğine sebep olur [8]. Kömürün yanması sonucu atmosfere karışan kirleticiler; ince tozlar, kükürt oksitler, azot oksitler, karbon dioksitler, hidrokarbonlar ve aldehitler olarak özetlenebilir [9]. Bu kirleticilerin çevreyi etkilemesi asit yağmurları ve atmosferdeki karbon dioksit $\left(\mathrm{CO}_{2}\right)$ artışı gibi durumlarla olmaktadır. Bu durum çevre sorunlarına neden olmaktadır. Asit yağmuru, $\mathrm{pH} 5.6$ 'dan küçük yağmur olarak tanımlanmaktadır. Asit yağmuruna, kükürt dioksitin $\left(\mathrm{SO}_{2}\right)$ ve azot dioksitin $\left(\mathrm{NO}_{2}\right)$ sülfürik asite $\left(\mathrm{H}_{2} \mathrm{SO}_{4}\right)$ ve nitrik asite $\left(\mathrm{HNO}_{3}\right)$ dönüşmesi neden olmaktadır [10]. $\mathrm{CO}_{2}$ ise güneşten gelen kısa dalga uzunluklu 1şınların dünyaya ulaşmasını engellemez fakat yeryüzünden yansitılan kızılötesi 1şınları absorbe eder. Böylece fosil yakıtlar atmosferde sera gazı emisyonlarını artırır [11]. Buna ek olarak, kömürün yanması sonucu oluşan külün bir bölümü baca gazları ile atmosfere karışmaktadır [12]. Bu kül, atmosferik partikül maddenin (PM) en önemli kısmını oluşturan $\mathrm{PM}_{10}$, aerodinamik çap1 $10 \mu \mathrm{m}$ ve altındaki boyuta sahip partikül madde olarak tanımlanmaktadır [13]. Bu partikül maddeler havada uzun süre asılı bir şekilde kalabilmekte [14] ve solunum yoluyla insan vücuduna girerek birçok hastalıklara neden olmaktadır. Bu nedenle partikül maddeler sağlıkla ilgili fraksiyon olarak da sınıflandırılabilir [15-18]. İnsan sağlığı üzerine etkileri dışında partikül maddeler güneş radyasyonunu etkilemesinden dolaylı iklimi etkilemektedir [19]. Aynı zamanda atmosferdeki partikül maddeler, çeşitli süreçlerden sonra çökelme yoluyla 
toprağı, suyu kirleterek diğer çevresel problemlere de neden olabilmektedir [20]. Yüksek kaliteli kömürlerin rezervlerinin azalması sonucu yüksek kükürt, azot ve ağır metaller içeren kalitesiz kömürlerin kullanılması ciddi çevre sorunlarına yol açmaktadır [21]. Bilindiği gibi ülkemizdeki kömür rezervlerinin çoğunluğunu linyit kömürü oluşturmaktadır [22]. Ancak linyit kömürü 1sıl değeri düşük ve kükürt, kül gibi kirletici madde oranları yüksek olan bir kömür olması sebebiyle daha fazla hava kirliliğine neden olmaktadır. Toplam dünya linyit rezervinin yaklaşık \%1.6's1 ülkemizde bulunmaktadır. Türkiye'deki linyitin karbon içeriği \%8.8-44.1 arasında, kül içeriği, \%5.2-59 arasında, nem içeriği \%1.2-57.6 arasında ve kükürt içeriği \% 0.2-10.6 arasında değişmektedir [23]. Ayrıca linyitin 1sıl değeri; $1100-5500 \mathrm{kcal} / \mathrm{kg}$ aralığındadır. Türkiye'deki toplam linyit rezervlerinin \% 75'nin 1sıl değeri $2500 \mathrm{kcal} / \mathrm{kg}$ 'ın altında, \%17'si 2500-3000 kcal $/ \mathrm{kg}$ arasında ve \% 8'i $3000 \mathrm{kcal} / \mathrm{kg}$ 'ın üstündedir [24].

Sonuç olarak, bu çalışmada günümüzde hava kirliliğinin önemli bir çevre sorunu olması ve enerji elde etmek amacıyla kullanılan fosil yakıtlardan kömürün bu çevre sorununda etkisinin oldukça fazla olması nedeniyle Ardahan ilinde kullanılan kömürün kalitesinin tespit edilmesi ve 1sınma amaçlı kömür tüketimi sonucu olabilecek çevre kirlenmesinin incelemesi amaçlanmıştır. Bunun için Ardahan ili genelinde satışı yapılan 8 farklı kömür bayisinden alınan numunelerin analizleri yapılarak satılan kömürde kalite tespiti ve çevrede oluşturduğu kirlilik araştırılmıştır. Kalite tespiti için kömürlerde; Üst Isı Değeri $(\mathrm{kcal} / \mathrm{kg})$, Kükürt (S) (\%), Nem (\%), Kül (\%), Uçucu Madde (\%), Sabit Karbon (\%), analizleri yapılmıştır. Bunun dışında Ardahan merkezinde Çevre ve Şehircilik Bakanlığının kurduğu Ulusal Hava Kalitesi İzleme Sistemi'ne bağlı ölçüm istasyonundan veriler alınarak kirlilik parametreleri $\left(\mathrm{SO}_{2}, \mathrm{CO}_{2}, \mathrm{CO}, \mathrm{NOx}, \mathrm{PM}_{10}\right)$ incelenmiştir. Ölçüm sonuçları Bakanlığa ait özel bir ağ (VPN) üzerinden GSM Modemler aracılığıyla Bakanlığın Çevre Referans Laboratuarı Veri İşletim Merkezine aktarılarak izlenmekte ve www.havaizleme.gov.tr adresinde eşzamanlı olarak yayınlanmaktadır [13].

\section{Materyal metot}

Ardahan ili, Doğu Anadolu Bölgesinde 1799 metre rakıma sahip olup 100809 kişilik nüfusa sahiptir. Batısında Artvin, güneybatısında Erzurum, güneyinde Kars illeri ve

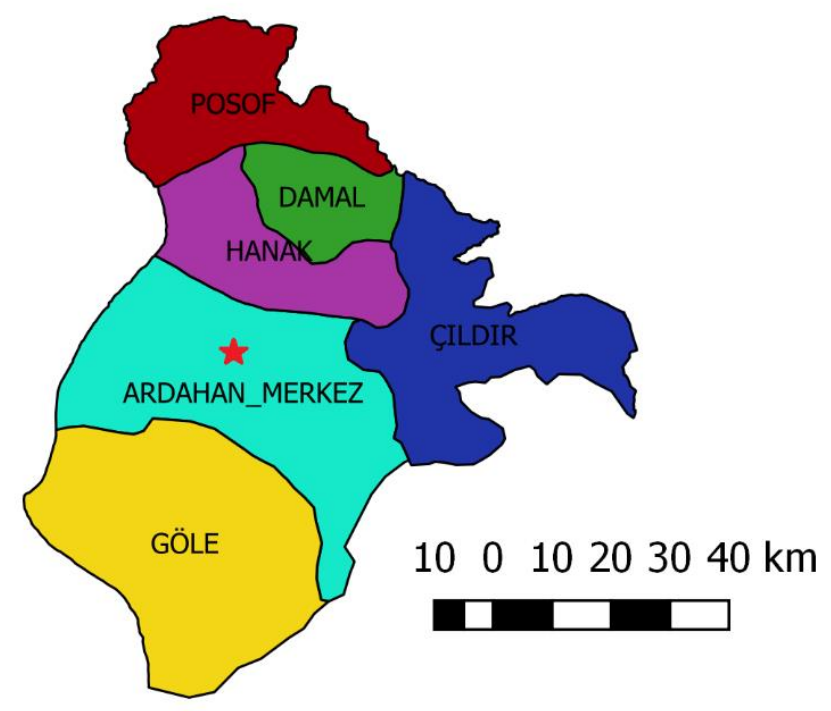

Şekil 1. Çalışma alanında bulunan hava kalitesi ölçüm istasyonunun yeri. 
doğusunda Gürcistan bulunmaktadır. Yüzölçümü 5576 km²'dir. Ardahan'da karasal iklim hâkimdir, yıllık ortalama hava sıcaklığı $3.7{ }^{\circ} \mathrm{C}$ 'dir ve kışın hava sıcaklığı $-30{ }^{0} \mathrm{C}$ 'nin altına düşmektedir.

$\mathrm{Bu}$ çalışmada analiz yapılacak kömürler Ardahan ili genelinden (Ardahan Merkez, Ardahan Halil Efendi Mahallesi, Göle, Çıldır, Damal, Posof, Hanak ilçeleri) temin edildi. Kömürün kalitesini tespit etmek için örnek alınan kömürler değirmende ögütüldükten sonra 100 mesh elekten geçirilmiştir ve çalışmada 100 mesh altı tanecikler kullanılmıştır. Analize hazırlanmış kömürlerde Üst Isı Değeri (kcal/kg), Kükürt (S) (\%), Nem (\%), Kül (\%), Uçucu Madde (\%) analizleri, Tablo 1'de gösterilen ilgili standartlara göre analiz edilmişlerdir.

Tablo 1. Kömür analizleri için ilgili standartlar.

\begin{tabular}{cc}
\hline Kömür Analizi & İlgili Standartlar \\
\hline Üst Is1 Değeri (kcal/kg) & TS 2678 \\
\hline Yanar Kükürt (S) veya Toplam Kükürt & TS 363- TS 329 TS 440 \\
$($ S) & TS 643- TS 330 TS 1042 \\
\hline Kül (\%) & TS 701 - TS 690- TS 438 \\
\hline Nem (\%) & TS 711 \\
\hline Uçucu Madde (\%) & TS 1593- TS 1612 \\
\hline Sabit Karbon & TS 652- TS 646
\end{tabular}

Kömürde Nem tayini Gemo DT104 markalı etüvde, Kül ve Uçucu madde tayini Protherm marka PLF 120/10 model kül firınında, Toplam Kükürt tayini Eltra marka CS 580 model Karbon kükürt cihazında ve Üst Isı Değeri tayini Ika marka C200 model Kalorimetrede yapılmıştır. Kömürün ihtiva ettiği \% S ve \% kül miktarına göre eşitlik (3)'ten bir yılda oluşan $\mathrm{SO}_{2}$ miktarı, eşitlik (4)'ten ise bir yılda oluşan kül miktarları hesaplanmıştır.

$\left(\frac{k g k o ̈ m u ̈ r}{1 y l l}\right) \times\left(\frac{\% S}{\% \text { kömür }}\right) \times\left(\frac{1 \mathrm{~mol} S}{32 \mathrm{gS}}\right) \times\left(\frac{1 \mathrm{~mol} \mathrm{SO} O_{2}}{1 \mathrm{~mol} \mathrm{~S}}\right) \times\left(\frac{64 \mathrm{gSO}_{2}}{1 \mathrm{~mol} \mathrm{SO}_{2}}\right)=\frac{\mathrm{kg} \mathrm{SO}_{2}}{y l l}$

$\left(\frac{k g k o ̈ m u ̈ r}{1 y l l}\right) x\left(\frac{\% k \text { ül }}{\% k \text { k̈mür }}\right)=\frac{k g k \ddot{u} l}{y l l}$

Bunun dışında Ardahan merkezinde Çevre ve Şehircilik Bakanlığı'nın kurduğu Ulusal Hava Kalitesi İzleme Sistemi'ne bağlı ölçüm istasyonundan veriler alınarak kirlilik parametreleri incelenmiştir. Bu Ulusal Hava Kalitesi İzleme Sistemi istasyonunda kirlilik parametreleri $\left(\mathrm{SO}_{2}, \mathrm{NO}_{2}, \mathrm{NO}, \mathrm{NOx}, \mathrm{PM}_{10}\right)$ otomatik cihazlarla ölçülmektedir [13].

\section{Bulgular ve tartışma}

Ardahan Çevre ve Şehircilik İl Müdürlüğünün verilerine göre; 2017 yılında Ardahan ili genelinde (Ardahan Merkez, Ardahan Halil Efendi Mahallesi, Göle, Çıldır, Damal, Posof, Hanak ilçeleri) kullanılan kömürün miktarı, 22172 ton ithal kömür ve 10835 ton yerli kömür olmakla birlikte toplam 33007 tondur. Isıtma amaciyla kullanılan kömürde nem, kül, kükürt, uçucu madde, sabit karbon ve 1sı değerleri analiz edilerek Tablo 2'de verilmiştir. 
Tablo 2. Isıtma amacıyla kullanılan fosil yakıtın genel özellikleri.

\begin{tabular}{|c|c|c|c|c|c|c|c|}
\hline & $\begin{array}{l}\text { Kalori } \\
\text { (g/cal) }\end{array}$ & $\% \mathrm{~S}$ & Kül (\%) & $\begin{array}{c}\text { Uçuculuk } \\
(\%)\end{array}$ & $\begin{array}{c}\text { Nem } \\
(\%)\end{array}$ & $\begin{array}{l}\text { Uçucu } \\
\text { Madde }\end{array}$ & $\begin{array}{c}\text { Sabit } \\
\text { Karbon }\end{array}$ \\
\hline \multicolumn{8}{|c|}{ Yerli Kömür } \\
\hline Yerli Kömür Standart1 & 4000 & 2.0 & $*$ & $*$ & $*$ & $*$ & $*$ \\
\hline Ardahan/Halilefendi & 4412 & 2.58 & 30.50 & 41.68 & 12.70 & 28.98 & 27.24 \\
\hline Çıldır Sosyal Yard. V. & 4189 & 2.10 & 36.49 & 34.95 & 15.67 & 21.78 & 56.17 \\
\hline \multicolumn{8}{|c|}{ İthal Kömür } \\
\hline İthal Kömür Standartı & 6200 & 0.9 & 14.0 & $*$ & 10.0 & $12-28$ & $*$ \\
\hline Ardahan/Merkez & 6590 & 0.78 & 14.93 & 31 & 8.42 & 22.58 & 54.07 \\
\hline Göle & 6327 & 0.79 & 14.28 & 42.11 & 9.20 & 38.91 & 43.61 \\
\hline Çıldır Tarım Kredi Koop. & 6724 & 0.68 & 13.27 & 28.48 & 7.15 & 21.33 & 58.25 \\
\hline Damal & 6609 & 0.71 & 14.98 & 28.85 & 8.67 & 20.18 & 60.17 \\
\hline Posof MYO & 6834 & 0.56 & 13.53 & 25.91 & 7.19 & 18.72 & 60.56 \\
\hline Hanak & 7052 & 0.54 & 13.94 & 25.37 & 7.15 & 18.23 & 6.65 \\
\hline
\end{tabular}

* Yönetmelikte ilgili standart bulunmamaktadır

Tablo 2 incelendiğinde Ardahan'da kullanılan yerli kömürün içeriklerinde çevre kirlenmesine neden olan kül ve kükürdün oldukça fazla olduğu görülmektedir. Yerli kömür \%2.1-2.58 aralığında kükürt ve \%30.5-36.49 aralığında kül; ithal kömür ise \%0.54-0.79 aralığında kükürt ve \%13.27-14.98 aralığında kül ihtiva etmektedir. Tablo 2'den anlaşıldığı gibi yerli kömürler standartların üzerinde kükürt ve küle sahiptirler. Bilindiği gibi yanma prosesinde kükürt $(\mathrm{S})$ oksijenle $\left(\mathrm{O}_{2}\right)$ reaksiyona girerek kükürtdioksit $\left(\mathrm{SO}_{2}\right)$ oluşturmaktadır. Denklem (2)' den anlaşıldığı gibi kükürtün yanması sonucunda kükürtün iki katı kükürt dioksit oluşmaktadır. Oysa yerli kömür \%2.1-2.58 aralığında kükürt ihtiva etmektedir. Bundan dolayı yerli kömürün yakılması sonucu $455070-559086 \mathrm{~kg}$ aralığında $\mathrm{SO}_{2}$ oluşmakta ve 3304675-3953692 kg aralığında kül oluşmaktadır. İthal kömürün yanması sonucundaysa $239458-350318 \mathrm{~kg}$ aralığında $\mathrm{SO}_{2}$ ve 2942224-3321366 kg aralığında kül oluşmaktadır. Sonuç olarak, Ardahan ili genelinde yerli ve ithal kömürün yakılması sonucunda toplam 694528-909404 kg aralığında $\mathrm{SO}_{2}$ ve $6246899-7275058 \mathrm{~kg}$ aralığında kül oluşmaktadır. Bunun için Ardahan'daki mevcut hava kirliğinin tamamına yakınını kullanılan kömürün oluşturduğu ifade edilebilir. Çünkü Ardahan'da hava kirletici özelliği olabilecek fabrika bulunmamaktadır. Kömür kullanımı sonucunda oluşan emisyonların büyük miktarının $\mathrm{PM}_{10}$ ve $\mathrm{SO}_{2}$ kaynaklı olduğu görülmektedir. $\mathrm{Bu}$ da yerli kömürün yüksek miktarda kükürt ve kül içermesinden kaynaklanmaktadır. Bunu Ardahan il merkezinde bulunan Ulusal Hava Kalitesi İzleme Sistemine bağlı ölçüm istasyonundan aldığımız kirlilik parametreleri de desteklemektedir (Şekil 2,3,4,5,6). 


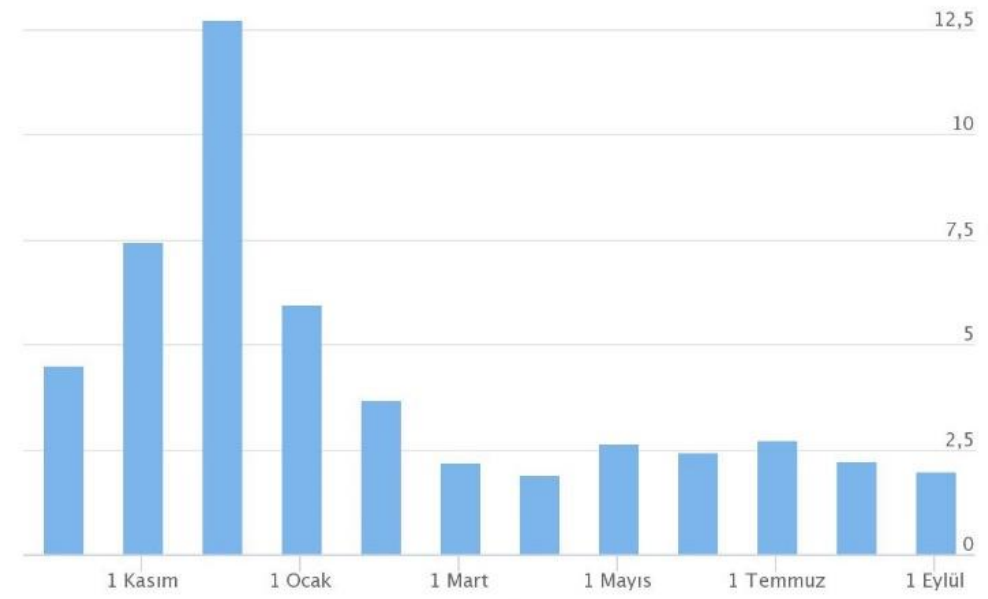

Şekil 2. 10/2017 - 09/2018 tarihleri arası NO değeri $\left(\mu \mathrm{g} / \mathrm{m}^{3}\right)$.

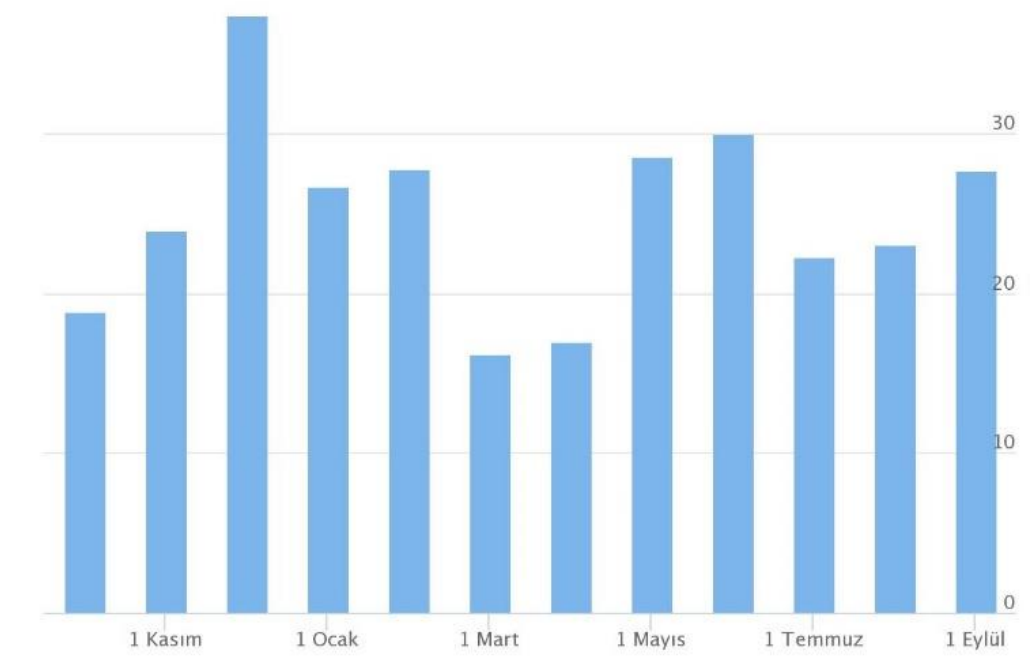

Şekil 3. 10/2017 - 09/2018 tarihleri arası $\mathrm{NO}_{2}$ değeri $\left(\mu \mathrm{g} / \mathrm{m}^{3}\right)$.

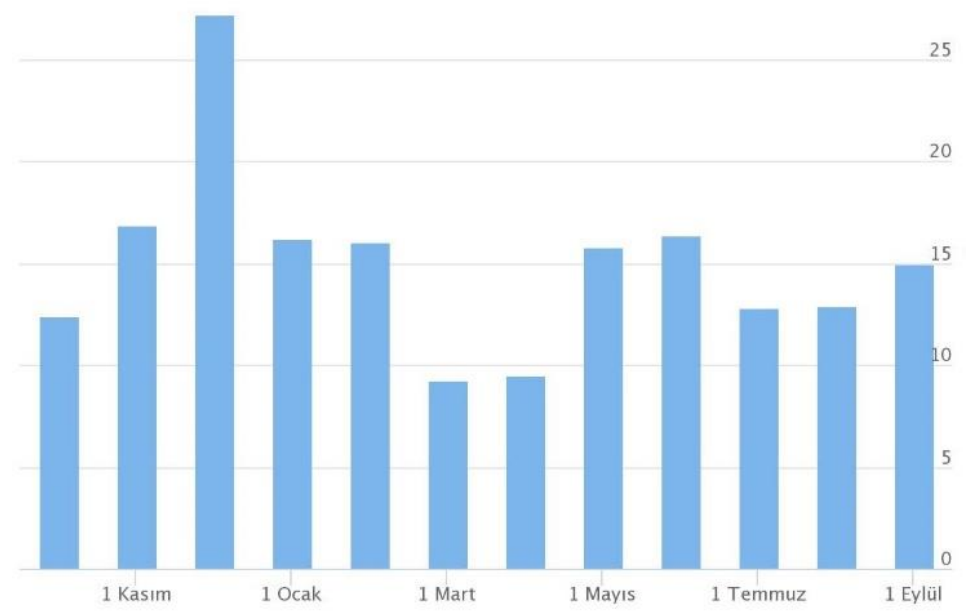

Şekil 4. 10/2017 - 09/2018 tarihleri arası NOx değeri $\left(\mu \mathrm{g} / \mathrm{m}^{3}\right)$. 


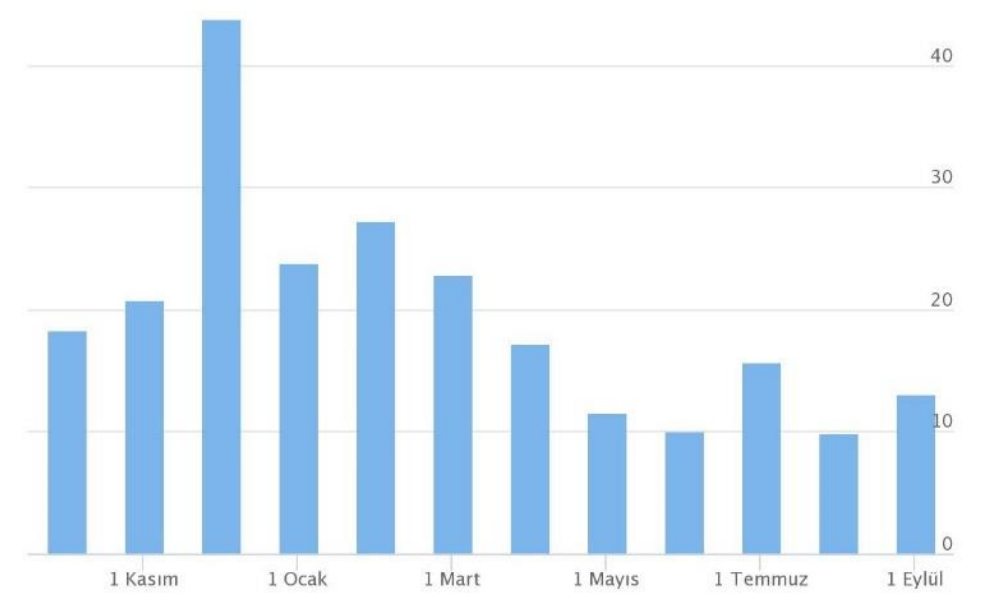

Şekil 5. 10/2017 - 09/2018 tarihleri arası $\mathrm{PM}_{10}$ değeri $\left(\mu \mathrm{g} / \mathrm{m}^{3}\right)$.

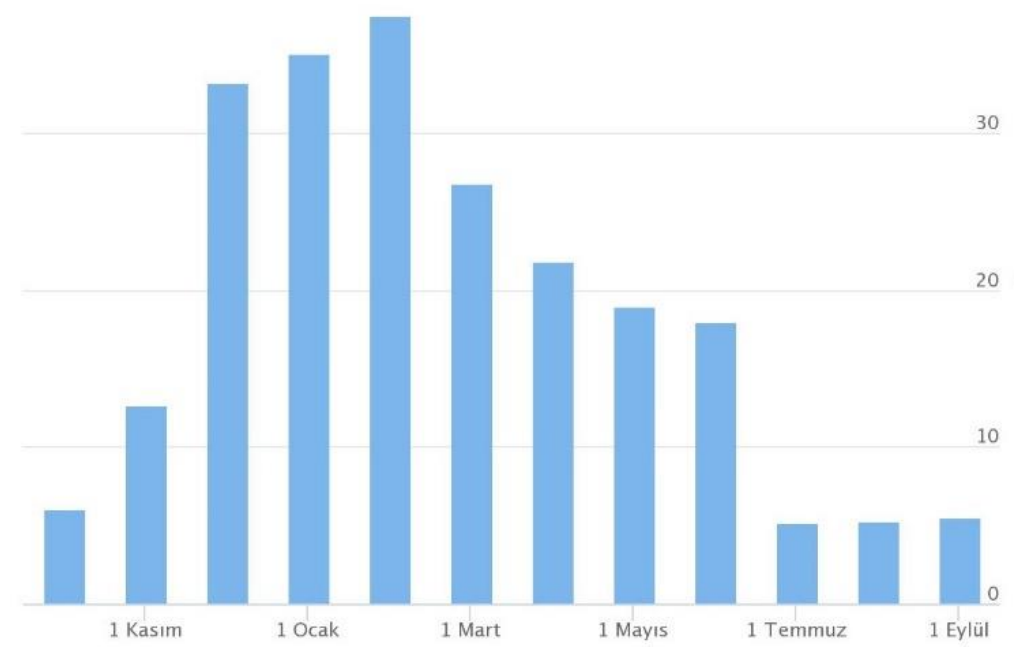

Şekil 6. 10/2017 - 09/2018 tarihleri aras1 $\mathrm{SO}_{2}$ değeri $\left(\mu \mathrm{g} / \mathrm{m}^{3}\right)$

Araştırma sahasının 2017 yılı Ekim ve 2018 yılı Eylül ayları arası rüzgâr hızı ve rüzgâr yönü dağılımının yer aldığı rüzgârgülü Şekil 7'de verilmiştir.

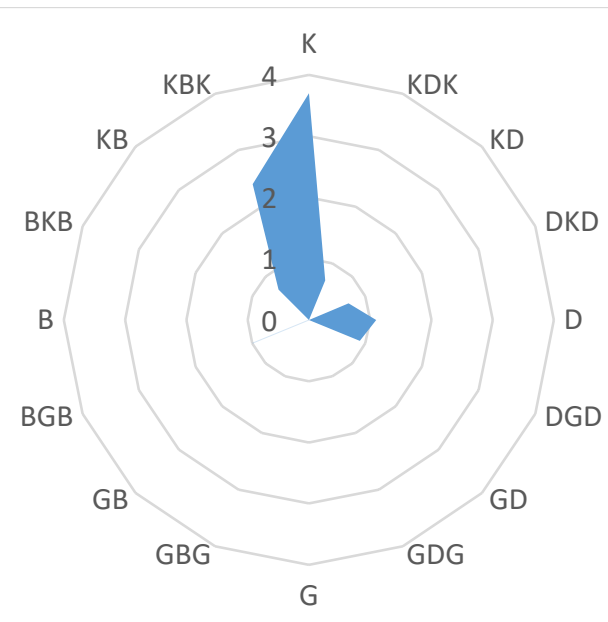

Şekil 7. Ardahan merkeze ait 10/2017 - 09/2018 tarihleri arası rüzgârgülü 
Şekil 7 incelendiğinde hâkim rüzgâr yönünün Kuzey, Kuzeybat1-Kuzey olduğu görülmektedir. Tablo 3'de ise Ekim 2017 ve Eylül 2018 tarihleri arası Ardahan'da aylık hâkim rüzgâr yönü ve ortalama rüzgâr hızı verilmiștir. Tablo 3 incelendiğinde rüzgâr hızının 0.7-1.3 m/sn arasında olduğu ve kömür tüketiminin fazla olduğu Kasım, Aralık, Ocak, Şubat aylarında rüzgâr hızının $0.7 \mathrm{~m} / \mathrm{sn}$ olduğu görülmektedir. Bu rüzgâr hızı bofor ölçeğine göre esinti olarak adlandırılmaktadır ve kirli havanın dağılmasını sağlayamamaktadır. Benzer sonuçlar birçok araştırmada da gözlenmiştir [25,26,27].

Tablo 3. Ardahan'da aylık hâkim rüzgâr yönü ve ortalama rüzgâr hızı (m/sn).

\begin{tabular}{ccccccccccccc}
\hline Y11/Ay & 1 & 2 & 3 & 4 & 5 & 6 & 7 & 8 & 9 & 10 & 11 & 12 \\
\hline \multirow{2}{*}{2017} & & & & & & & & & & D & KB & DKD \\
& & & & & & & & & & 1.1 & 0.7 & 0.7 \\
\hline \multirow{2}{*}{2018} & K & KKD & K & KKB & KKB & K & K & BGB & DGD & & & \\
& 0.7 & 0.7 & 1.1 & 1.3 & 1.1 & 0.9 & 1.0 & 1.0 & 0.9 & & & \\
\hline
\end{tabular}

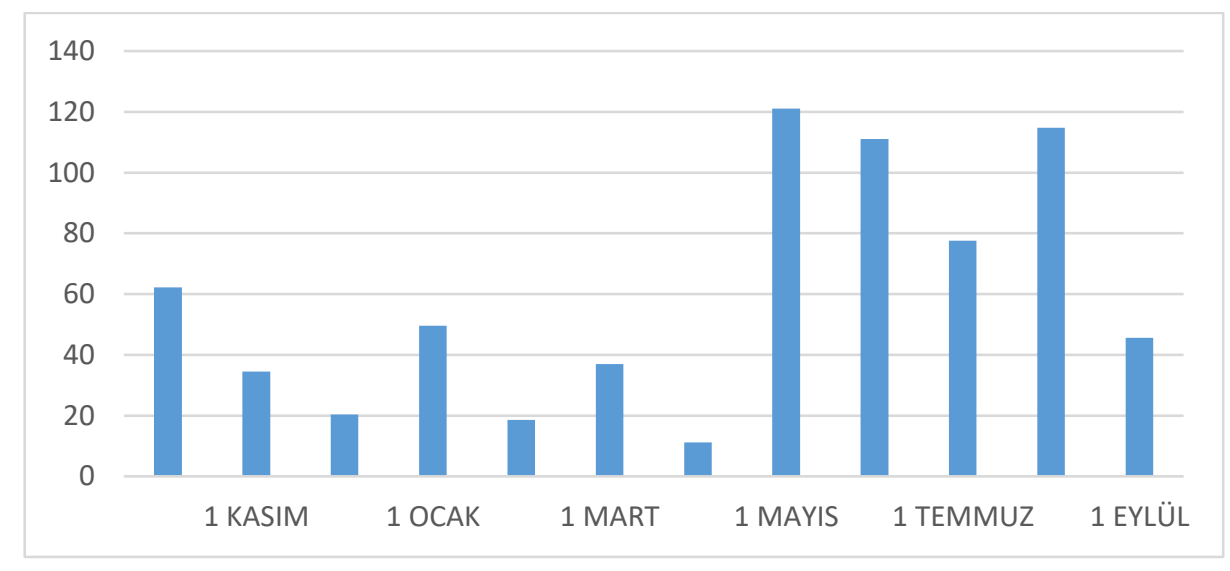

Şekil 8. 10/2017 - 09/2018 tarihleri arası ortalama yağış $\left(\mathrm{mm}=\mathrm{kg} / \mathrm{m}^{2}\right)$.

Ardahan'da karasal Doğu Anadolu termik rejimi olduğu için yağışlar yaz aylarında gerçekleşmektedir [28]. Şekil 8 incelendiğinde aylık bazda ortalama yağış miktarının yaz aylarına kıyasla kömür tüketiminin fazla olduğu Kasım, Aralık, Ocak, Şubat aylarında düşük olduğu görülmektedir. Bu sebeple 1sınma amaçlı kömür tüketiminin fazla olduğu bu aylardaki yağış miktarı hava kirliliğinin seyrelmesine az etki etmektedir.

Hava kirliliğinin çevre üzerindeki zararlı etkilerini önlemek veya azaltmak için 6 Haziran 2008 tarih ve 26898 sayılı Resmi Gazete 'de yayımlanan Hava Kalitesi Değerlendirme ve Yönetimi (HKDY) Yönetmeliği yürürlüğe girmiştir. Yönetmelikte Avrupa Birliği'nin (AB) hava kalitesi limit değerine uyum sağlanması da hedeflenmiştir. Türkiye HKD Yönetmeliğinde de kirleticiler için bir sınırlama getirilmiş ve bu limit değerler Tablo 4'te verilmiştir. 
Tablo 4. Türkiye için kirleticilerin limit değerleri.

\begin{tabular}{ccc}
\hline & Ortalama süre & Limit de ğer \\
\hline \multirow{2}{*}{$\mathrm{SO}_{2}$} & Saatlik & $350 \mu \mathrm{g} / \mathrm{m}^{3}$ \\
\cline { 2 - 3 } & 24 saatlik & $125 \mu \mathrm{g} / \mathrm{m}^{3}$ \\
\hline \multirow{2}{*}{$\mathrm{NO}_{2}$} & Saatlik & $200 \mu \mathrm{g} / \mathrm{m}^{3}$ \\
\cline { 2 - 3 } & 24 saatlik & $40 \mu \mathrm{g} / \mathrm{m}^{3}$ \\
\hline $\mathrm{NO}_{\mathrm{x}}$ & Y1llik & $30 \mu \mathrm{g} / \mathrm{m}^{3}$ \\
\hline \multirow{2}{*}{$\mathrm{PM}_{10}$} & 24 Saatlik & $50 \mu \mathrm{g} / \mathrm{m}^{3}$ \\
\cline { 2 - 3 } & Y1llik & $40 \mu \mathrm{g} / \mathrm{m}^{3}$ \\
\hline
\end{tabular}

Ardahan merkezindeki hava kalitesi izleme istasyonlarından elde edilen aylık veriler incelendiğinde (Şekil 2, Şekil 3, Şekil 4, Şekil 5, Şekil 6) $\mathrm{NO}, \mathrm{NO}_{2}, \mathrm{NOx}, \mathrm{PM}_{10}, \mathrm{SO}_{2}$ değerlerinin kış aylarında yüksek olduğu gözlemlense de Tablo 3'de verilmiş kirleticilerin limit değerlerini aşmadığı anlaşılmaktadır. Verileri ay bazında incelediğimizde en yüksek değerin Aralık ayında olduğu $\left(\mathrm{NO}=12.65 \mu \mathrm{g} / \mathrm{m}^{3}, \mathrm{NO}_{2}=37.5\right.$ $\mu \mathrm{g} / \mathrm{m}^{3}, \mathrm{NO}_{\mathrm{x}}=27 \mu \mathrm{g} / \mathrm{m}^{3}, \mathrm{PM}_{10}=43.8 \mu \mathrm{g} / \mathrm{m}^{3}$ ) görülmektedir. Kükürt dioksitin Aralık, Ocak ve Şubat aylarında $30 \mu \mathrm{g} / \mathrm{m}^{3}$ değerini aştı̆̆ 1 , en düşük değerlerin ise $\left(10 \mu \mathrm{g} / \mathrm{m}^{3}\right.$ altında) Temmuz, Ağustos, Eylül, Ekim aylarında olduğu anlaşılmaktadır. Soğuk aylarda 1sıtmaya olan ihtiyaçtan dolayı yakıt tüketiminin artması $\mathrm{SO}_{2}$ değerini de artırmaktadır (Şekil 6). Buna aynı zamanda soğuk aylarda atmosfere salınan kükürt dioksitin havada yayılmasının yavaşlaması da neden olmaktadır. Benzer sonuçlar diğer araştırmalarda da tespit edilmiştir [29,30].

Şekil 3'te görüldüğü gibi $\mathrm{NO}_{2}$ kirletici değerinin yılın 9 ayında $20 \mu \mathrm{g} / \mathrm{m}^{3}$ 'ten yüksek olması, tüketilen kömürün dışında arabaların egzoz gazlarının da havayı kirlettiğini düşünmemize neden olmuştur. Ayrıca yılın Mart ve Nisan aylarında azot dioksit gazının konsantrasyonunun $20 \mu \mathrm{g} / \mathrm{m}^{3}$ 'ten düşük olmasının nedeni olarak bu aylarda artan yağışlarla $\mathrm{NO}_{2}$ 'nin atmosferden uzaklaşması düşünülmektedir.

Şekil 5'te 10/2017 - 09/2018 tarihleri arasındaki $\mathrm{PM}_{10}$ değeri $\left(\mu \mathrm{g} / \mathrm{m}^{3}\right)$ görülmektedir. Diğer kirleticilerde olduğu gibi $\mathrm{PM}_{10}$ değeri de kış aylarında daha yüksek bulunmaktadır. Bunun da kullanılan kömürden kaynaklandığı düşünülmektedir. $\mathrm{PM}_{10}$ değerinin diğer kirleticilerden farklı olarak Temmuz ayında yüksek olmasının nedeni ise, güneyden ve doğudan gelen toz taşınmalarından kaynaklanabileceği düşünülmektedir. Benzer sonuçlar diğer araştırmalarda da bulunmaktadır [13].

\section{Sonuç ve öneriler}

Bu çalışmada 10/2017 - 09/2018 tarihleri arası Ardahan ilinde 1sınma için kullanılan kömür miktarı ve bu kömürün yanması sonucu çevrenin kirlenmesine sebep olan kirletici parametreler tespit edilmiştir. Ardahan ili genelinde bu tarihler arası ısınma amaçlı 22172 ton ithal ve 10835 ton yerli olmakla birlikte toplam 32907 ton kömür kullanıldığ belirlendi. $\mathrm{Bu}$ kömürün yanması sonucunda yaklaşık 788 ton $\mathrm{SO}_{2}$ ve 6400 ton kül oluşmaktadır. Bunun dışında Ardahan merkezinde Çevre ve Şehircilik Bakanlığı'nın kurduğu Ulusal Hava Kalitesi İzleme Sistemi'ne bağlı ölçüm istasyonundan veriler alınarak kirlilik parametreleri incelenmiştir. Bulgulara gör kirlilik parametrelerinin $\left(\mathrm{SO}_{2}\right.$, $\mathrm{NO}_{2}, \mathrm{NO}, \mathrm{NO}_{\mathrm{X}}, \mathrm{PM}_{10}$ ) değerleri Türkiye HKDY Yönetmeliğindeki limit kirletici 
değerlerinin altında olduğu görülmüştür. Ancak Ardahan merkezde kış aylarındaki kirletici parametrelerin konsantrasyonlarının, yaz aylarındaki değerlerden fazla olduğu saptand1. Özellikle $\mathrm{PM}_{10}$ değeri 4 kat, $\mathrm{SO}_{2}$ ise 7 kat yüksektir. Sonuç olarak öneriler aşağıda maddeler halinde verilmiştir.

- Kirletici parametrelerin izlenebilmesi için mevcut ölçüm istasyonunda ölçülmesi mümkün olmayan $\mathrm{CO}, \mathrm{CO}_{2}, \mathrm{VOC}, \mathrm{O}_{3}$ ve $\mathrm{PM}_{2.5}$ ölçüm cihazlarının alınması,

- Ardahan merkezde doğalgaz dağıtım hizmetlerinin hızlandırılması ve bunun il geneline yayılmas1,

- Şehir merkezinde sadece 1sı değeri yüksek, kül ve kükürt değerleri düşük kömürlerin kullanılmasına izin verilmesi,

- Kış aylarında hava kirliliğinin yükselmemesi amacıyla doğalgaz kullanımının teşvik edilmesi gibi konularda halkın bilgilendirilmesi önerilmektedir.

\section{Teșekkür}

Yazarlar, bu çalışmanın yapılmasında 2017/003 nolu projeye olan desteği nedeni ile, Ardahan Üniversitesi Bilimsel Araştırmalar Koordinatörlüğüne teşekkür eder.

\section{Kaynaklar}

[1] Gönüllü, T. Endüstriyel Kirlenme Kontrolü. Birsen yayınevi 466 s İstanbul Türkiye. (2004).

[2] Zhang YL, Cao F, Is it time to tackle PM2.5 air pollutions in China from biomassburning emissions? Environmental Pollution, 202, 217-219, (2015).

[3] Xu B, Luo LQ, Lin, BQ, A dynamic analysis of air pollution emissions in China: Evidence from nonparametric additive regression models, Ecological Indicators, 63, 346-358, (2016).

[4] Durmaz A, Ercan Y, Yanmadan kaynaklanan Hava Kirliliğinin ve Kontrolü, Uluslararası Yanmadan kaynaklanan Hava Kirliliği Sempozyumu, Ankara, (1987).

[5] Elliot MA, Chemistry of Coal Utilization Second Supplementary Volume, (1981).

[6] Başaran M, Kömür yakıtlı santraller. Türkiye'de Termik Santraller, Ankara, 265, (2017).

[7] World coal institue, Coal meeting the climate challenge, (2009)

[8] Hilmioğlu B, Hava Kalitesi Kontrolü Laboratuvar'ında Akreditasyon Uygulamaları, Eğitim Notları, TÜBİTAK MAM Enerji ve Çevre Araştırma Enstitüsü Kurs Notları, Kocaeli, 46-69, (2004).

[9] Edgar TF, Coal Processing and Pollution Control, (1983).

[10] Rahmat M, Maulina W, Rustami E, Azis M, Budiarti DR, Seminar KB, Alatas H, Performance in real condition of photonic crystal sensor based $\mathrm{NO}_{2}$ gas monitoring system, Atmospheric Environment, 79, 480-485, (2013).

[11] Bauer N, Bosetti V, Hamdi-Cherif M, Kitous A, McCollum D, Mejean A, van Vuuren $\mathrm{D}, \mathrm{CO}_{2}$ emission mitigation and fossil fuel markets: Dynamic and international aspects of climate policies, Technological Forecasting and Social Change, 90, 243-256, (2015).

[12] Iovino P, Canzano S, Leone V, Berto C, Salvestrini S, Capasso S, Contribution of vehicular traffic and industrial facilities to PM concentrations in a suburban area of Caserta (Italy), Environ Sci Pollut Res, 21, 13169-13174, (2014). 
[13] Dolar A, Saraç HTK, Türkiye'nin. Doğu İllerindeki hava kalitesinin $\mathrm{PM}_{10}$ yönüyle incelenmesi, Iğdır Üniversitesi Fen Bilimleri Enstitüsü Dergisi, 5, 25-32, (2015).

[14] Kim K, Hong Y, Szulejko J, Kang C, Chambers S, Feng XB, Airborne iron across major urban centers in South Korea between 1991 and 2012, Science of the Total Environment, 550, 309-320, (2016).

[15] Bollati V, Marinelli B, Apostoli P, Bonzini M, Nordio F, Hoxha M, Baccarelli A, Exposure to Metal-Rich Particulate Matter Modifeies the Expression of Candidate MicroRNAs in Peripheral Blood Leukocytes, Environmental Health Perspectives, 118(6), 763-768, (2010).

[16] Boisa N, Entwistle J, Dean JR, A new simple, low-cost approach for generation of the PM fraction from soil and related materials: Application to human health risk assessment, Analytica Chimica Acta, 852, 97-104, (2014).

[17] Kim K, Kabir E, Kabir S, A review on the human health impact of airborne particulate matter, Environment International, 74, 136-143, (2015).

[18] Correa AX, Cotelle S, Millet M, Somensi CA, Wagner TM, Radetski CM, Genotoxicity assessment of particulate matter emitted from heavy-duty dieselpowered vehicles using the in vivo Vicia faba L. micronucleus test, Ecotoxicology and Environmental Safety, 127, 199-204, (2016).

[19] Kabatas B, Unal A, Pierce RB, Kindap T, Pozzoli L, The contribution of Saharan dust in PM concentration levels in Anatolian Peninsula of Turkey, Science of the Total Environment, 489, 413-421, (2014).

[20] Bayraktar H, Erzurum Kent Atmosferinde Partikül Madde Kompozisyonu, Atatürk Üniversitesi Fen Bilimleri Enstitüsü. Doktora Tezi. (2006).

[21] Hein KRG, Bemtgen J, EU clean coal technology co-combustion of coal and biomass, Fuel Processing Technology, 54, 159-169, (1998).

[22] Ersin M, Türkiye'de linyit kömürlerinin enerji kaynağı olarak önemi. Y. Lisans tezi, İstanbul Üniversitesi Sosyal Bilimler Enstitüsü, İstanbul. (2006).

[23] Usta K, Kutluk H, Eskişehir-Alpu linyitlerinin fiziksel ve kimyasal özellikleri, Bilim ve Teknoloji Dergisi A-Uygulamalı Bilimler ve Mühendislik, 15(1), 5167, (2014).

[24] Şengüler İ, Lignite Exploratıons In Turkey: New Projects And New Reserves. Twenty - Seventh Annual International Pittsburgh Coal Conference, IstanbulTurkey. (2010).

[25] Ünal İ. B, Duran A, Şehirleşmede yanlış yer seçiminin hava kirliliği üzerine olan etkisine bir örnek: Kastamonu şehri, Coğrafya Dergisi, 18, 71-88, (2009).

[26] Sever R. Malatya'daki hava kirliliğine coğrafi bakış, Doğu Coğrafya Dergisi, 13 (20), 59-76. (2008).

[27] Kunt F, Dursun Ş, Konya merkezinde hava kirliliğine bazı eteorolojik faktörlerin etkisi, Ulusal Çevre Bilimleri Araştırma Dergisi, 1, 1, 54-61, (2018).

[28] Atalay İ, Uygulamalı klimatoloji. Meta basım 600 s. İzmir Türkiye. (2010).

[29] McKenzie J, Pinger R, Kotecki JE, An introduction to community health: Jones \& Bartlett Publishers. (2011).

[30] Stellman M, Encyclopaedia of occupational health and safety: International Labour Organization. (1998). 